\title{
Valores humanos e satisfação no trabalho de professores e servidores técnico-administrativos de uma universidade pública
}

Human values and job satisfaction of teachers and technical-administrative staff at a public university Los valores humanos y la satisfacción laboral de los docentes y trabajadores técnicos y administrativos en una universidad pública

Thiago Francisco de ANDRADE ${ }^{1, a}$

Silvânia da Cruz BARBOSA ${ }^{\text {b }}$

Sandra SOUZA ${ }^{a}$

Jansen Souza MOREIRA ${ }^{\text {b }}$

Universidade Federal da Paraíba, João Pessoa, PB, Brasila, Universidade Estadual da Paraíba, Campina Grande, $\mathrm{PB}, \mathrm{Brasil}^{\mathrm{b}}$

Resumo Esta pesquisa teve como objetivo principal investigar o poder preditivo dos valores humanos e suas subfunções sobre a satisfação no trabalho em professores e servidores técnico-administrativos de uma universidade pública. Para tanto, contou com a participação de 192 profissionais, predominantemente professores $(60,9 \%)$, homens $(55,2 \%)$, com idade variando de 23 a 67 anos. Os participantes responderam a um protocolo composto por duas escalas: Escala de Satisfação no Trabalho (EST-R) e Questionário dos Valores Básicos (QVB), bem como a uma Ficha Sociodemográfica. Os resultados apontam que a dimensão Chefia é fonte de maior satisfação entre as duas categorias profissionais, enquanto a maior fonte de insatisfação entre os técnicoadministrativos é com a dimensão Promoções. Observou-se que a satisfação no trabalho de docentes e técnicos possui diferentes antecedentes axiológicos, como a dimensão Colegas, predita pelo valor Emoção na amostra de docentes, e pelo valor Estabilidade pessoal entre os técnicos. Considera-se que os resultados desta pesquisa poderão fornecer subsídios para a implementação de políticas organizacionais, bem como oferecer uma contribuição para o campo de estudo, no que concerne à compreensão das relações entre afetos vivenciados no trabalho e características individuais.

Palavras-chave:

Satisfação no trabalho; valores humanos; professor universitário; técnico-administrativo universitário.

Abstract This research aimed to investigate the predictive power of human values and their subfunctions on job satisfaction among teachers and technical administrative staff of a public university. The study involved the participation of 192 professionals, mostly teachers (60.9\%), men (55.2\%), aged 23-67 years. The participants answered a questionnaire consisting of two scales: Job Satisfaction-short version $(E S T-R)$ and the Basic Values Questionnaire $(Q V B)$, plus a sociodemographic data sheet. The results indicate that the Relationship with supervisors is the greatest source of satisfaction among the two professional categories, while the major source of dissatisfaction among the technical-administrative group lies in the Promotion policy dimension. It was observed that job satisfaction of teachers and technicians have different axiological backgrounds; for example the satisfaction with Peers relationship was predicted by the value Emotion, among teachers, while it was predicted by the value Personal stability, among the technical staff. We believe that the results of this research can support the implementation of organizational policies as well as contribute to this field of study, with regard to understanding the relationships between emotions experienced at work and individual characteristics.

Keywords:

Job satisfaction; human values; college teachers; technical staff.

1 Endereço para correspondência: Rua General Canabarro, 485, Paratibe, Paulista, PE, Brasil 53415-307. Email: thiagoandradepsi@ gmail.com 
Esta investigación tuvo como objetivo investigar la capacidad de predicción de los valores humanos y sus subfunciones en la satisfacción laboral de los profesores y el personal técnico y administrativo de una universidad pública. Contó con la participación de 192 profesionales, en su mayoría profesores (60,9\%), hombres (55,2\%), con edades entre 23-67 años. Los participantes respondieron a una encuesta que incluyó dos escalas: Escala de Satisfacción Laboral $(E S T-R)$ y el Cuestionario de Valores Básicos (QVB), y una ficha de datos sociodemográficos. Los resultados muestran que la Relación con los jefes es mayor fuente de satisfacción entre las dos categorías profesionales, como la mayor fuente de insatisfacción entre los administradores técnicos es la dimensión Promociones. Se observó que la satisfacción laboral de los docentes y técnicos tiene diferentes antecedentes axiológicos; como por ejemplo la dimensión Colegas se predice por el valor de la Emoción en la muestra de los docentes, y el valor Estabilidad del personal en la muestra de los técnicos. Se considera que los resultados de esta investigación pueden proporcionar ideas para implementar políticas organizacionales, así como hacer una contribución al campo de estudio, en cuanto a la comprensión de la relación entre las emociones experimentadas en el trabajo y las características individuales.

Palabras-clave:

Satisfacción laboral; valores humanos; profesor universitario; personal técnico y administrativo.

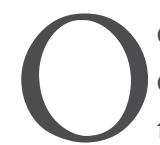

estudo das relações estabelecidas entre o homem e seu trabalho, bem como entre ele e as organizações, é perpassado por uma série de reconfigurações. Nesse cenário, o interesse pelos afetos vivenciados no trabalho vem estimulando estudos científicos no campo da psicologia do trabalho e das organizações desde meados do século XX, tendo como destaque as variáveis motivação (Maslow, 1970) e satisfação no trabalho (Herzberg, 1971), as quais têm sido relacionadas, nos estudos atuais, à incidência de transtornos psíquicos menores, a exemplo do estresse ocupacional e da síndrome de burnout (Carlotto \& Câmara, 2007; Maslach, 2009; Tamayo, 2001).

Noutro espectro, tanto autores do século passado (p. ex., Locke, 1969, 1976, 1984) como os da atualidade (p. ex., Tamayo \& Paschoal, 2003) têm proposto incluir os valores do trabalhador nos modelos explicativos da satisfação no trabalho. Compartilhando desse interesse, esta pesquisa tem como objetivo investigar o poder preditivo dos valores humanos sobre a satisfação no trabalho em docentes e profissionais técnico-administrativos da Universidade Estadual da Paraíba (UEPB).

A UEPB é uma instituição de nível superior, vinculada à Secretaria de Educação e Cultura do Estado da Paraíba, que tem como atividades-fim o ensino, a pesquisa e a extensão, exercidas diretamente pelo corpo docente, com o apoio dos profissionais técnico-administrativos universitários, responsáveis pelas atividades-meio.

As diversas características do trabalho docente universitário, como carga de trabalho excessiva - tanto em termos temporais quanto de atribuições, a exemplo dos professores que acumulam simultaneamente atividades de ensino, pesquisa e extensão -, pressão institucional para produção acadêmico-científica, participação em comissões, entre outras, acaba tornando esses profissionais vulneráveis a uma série de transtornos psíquicos, notadamente o estresse ocupacional e, com maior incidência, a síndrome de burnout (Carlotto, 2004, 2010; Carlotto \& Câmara, 2007; Garcia \& Benevides-Pereira, 2003).

A admissão de professores na UEPB ocorre por diferentes vias, em função dos diferentes regimes de trabalho existentes na instituição. Na maioria das vezes, são admitidos em caráter efetivo, via concurso público de provas e títulos, com critérios estabelecidos por cada departamento, ou podem, ainda, ser contratados em caráter temporário (professores substitutos), via seleção simplificada. Os professores efetivos gozam de benefícios, como planos de ascensão funcional horizontal (em função do tempo) e vertical (em função da obtenção de títulos), com repercussão direta em seus salários. Uma terceira categoria é formada pelos professores visitantes ou bolsistas, que desempenham suas atividades em caráter temporário e são financiados por órgãos de fomento em diversas instâncias (p. ex., CNPq e CAPES).

Os técnico-administrativos universitários, por sua vez, compreendem uma variedade de atividades e atribuições. Em virtude disso, são subdivididos em três classes, A, B e C, de acordo com o nível de complexidade da tarefa ou mesmo do grau de escolaridade exigido para sua investidura. Cada uma dessas classes congrega um sem-número de funções, descritas no Manual de Cargos, Funções e Competências próprio da universidade (Universidade Estadual da Paraíba, 2008). Em geral, esses profissionais são admitidos através de concursos públicos, contudo, dependendo da necessidade da instituição, alguns podem ser admitidos temporariamente e em regime especial para exercer serviços técnicos de consultorias, bem como atividades muito específicas que 
não constam no quadro funcional da instituição, sendo denominados de técnico-administrativos comissionados (Lei 13.696/2007).

Este estudo abarcou docentes e técnico-administrativos universitários do campus I, situado na cidade de Campina Grande (PB). Esse campus compreende os seguintes centros: Ciências Biológicas e da Saúde (CCBS), Ciências e Tecnologia (CCT), Educação (CEDUC), Ciências Jurídicas (CCJ) e Ciências Sociais Aplicadas (CCSA).

Para a presente pesquisa, foi adotado o conceito de satisfação no trabalho proposto por Siqueira (1995, 2008), sendo entendido como um sentimento experimentado pelo trabalhador em resposta às situações laborais; de modo que se encontraria satisfeito na medida em que percebe no seu trabalho a possibilidade de realizar suas metas e objetivos valorizados. Os valores humanos, por sua vez, serão abordados na perspectiva teórica de Gouveia (1998, 2003, 2013) e Gouveia, Milfont, Fischer e Coelho (2009), segundo a qual eles estão situados na esfera das características individuais, e dizem respeito às prioridades axiológicas, um sistema de conceitos que tem a característica de guiar as ações e a avaliação de eventos, comportamentos ou pessoas.

Diante do exposto, cabe o seguinte questionamento: como se relacionam os valores de profissionais de uma universidade pública, em especial docentes e profissionais técnico-administrativos, com seus níveis de satisfação no trabalho?

Por lidar diretamente com as atividades-fim de uma universidade (ensino, pesquisa e extensão), os professores, juntamente com o corpo discente, são os responsáveis pela reflexão, pela crítica e pelo desenvolvimento científico de estados e mesmo de nações. Depreende-se, assim, a importância de se estudar a percepção dos professores acerca das condições em que exercem o seu ofício, uma vez que o bom andamento de suas atividades está muito relacionado aos afetos vivenciados no trabalho.

Os profissionais técnico-administrativos, por sua vez, são a categoria de apoio às atividades universitárias. Assim, trata-se de um grupo que desempenha atividades-meio, fornecendo apoio técnico, burocrático e logístico às atividades-fim supracitadas. Sua importância, nesse caso, configura-se como capital, haja vista que sem suas atividades os objetivos da instituição seriam sobremaneira obstados.

A satisfação no trabalho de técnicos e professores, dependendo de suas potenciais consequências para a saúde, pode repercutir positiva ou negativamente tanto na qualidade do ensino/aprendizagem, quanto no desenvolvimento científico e nos serviços prestados à sociedade (Martinez \& Paraguay, 2003). O perfil axiológico, por outro lado, estaria intrinsecamente relacionado com as bases cognitivas que guiam as ações e as avaliações dos indivíduos, também em situações de trabalho (Calvosa, Serra, \& Almeida, 2011; Calvosa, Silva, Serra, \& Almeida, 2011), sugerindo a necessidade de sua melhor visualização no ambiente laboral, além de maior compreensão sobre as formas de relacionamento com outras variáveis laborais, nesse caso, a satisfação no trabalho.

Martinez e Paraguay (2003) apontam que há definições imprecisas na literatura sobre o que seria satisfação no trabalho, em virtude de sua proximidade com conceitos correlatos, a exemplo da motivação (Maslow, 1970). Apesar de esses conceitos estarem intimamente relacionados, a motivação diz respeito a uma tensão gerada por uma necessidade emergente que impulsiona o indivíduo à ação. É nesse sentido que, por exemplo, segundo Maslow (1970), a motivação consiste no movimento executado pelo indivíduo em direção ao topo da chamada Hierarquia das Necessidades Básicas. Na medida em que as necessidades fisiológicas, situadas à base da hierarquia, são supridas (p. ex., alimentação, sexo, segurança, etc.), o indivíduo é impelido a buscar a satisfação das necessidades que estão nos níveis imediatamente superiores da escala (p. ex., prestígio, autorrealização, etc.). A satisfação, por sua vez, diz respeito não à tensão, mas ao atendimento da necessidade que a gerou (Martinez \& Paraguay, 2003). Outros autores clássicos, como Herzberg (1971) e Locke (1969, 1976, 1984), também ofereceram discussões acerca do conteúdo, antecedentes e dimensionalidade desses construtos.

Neste estudo, a satisfação no trabalho será compreendida como uma variável de natureza emocional ou afetiva, proveniente da avaliação feita pelo trabalhador das condições psicossociais de seu trabalho e a consequente atitude em relação a ela (Martinez \& Paraguay, 2003; Paris \& Omar, 2008; Silva, 2015; Siqueira \& GomideJúnior, 2004). Tal noção forma uma das bases do modelo de bem-estar no trabalho formulado por Siqueira (1995, 2008), Siqueira e Padovam (2008), Siqueira e Martins (2013), Siqueira, Orengo e Peiró (2014), no qual a satisfação no trabalho é um construto formado por cinco dimensões que indicam o quanto um indivíduo experimenta vivências prazerosas no trabalho: (a) Satisfação com os colegas; (b) Satisfação com o salário; (c) Satisfação com a chefia; (d) Satisfação com a natureza do trabalho e (e) Satisfação com as promoções. Essas 
dimensões realçam a importância das relações estabelecidas entre o trabalhador em atividade e três outros elementos/entidades: seus pares, seu trabalho e a organização em que trabalham.

Segundo o pressuposto de que a satisfação no trabalho compreende o nível de contentamento ou avaliação positiva que o trabalhador expressa em relação ao seu trabalho (Martinez \& Paraguay, 2003; Paris \& Omar, 2008; Siqueira \& Gomide-Júnior, 2004), alguns autores (Locke, 1969, 1976, 1984; Tamayo \& Paschoal, 2003) têm proposto incluir os valores do trabalhador nos modelos explicativos da satisfação no trabalho. $\mathrm{O}$ trabalhador se encontraria satisfeito na medida em que percebe no seu trabalho a possibilidade de realizar suas metas e objetivos valorizados. Diante do exposto, decidiu-se incluir os valores humanos como a variável antecedente a ser testada neste estudo.

A literatura aponta a importância dos valores, como satisfação no trabalho e comprometimento organizacional, na relação com as variáveis organizacionais. Contudo, tal relação tem sido estudada mais frequentemente com os valores organizacionais (Cavadas, 2014; Ferreira \& Assmar, 2004; Tamayo, 1998), sendo poucos os estudos com os valores humanos (Tamayo, 2005; Tamayo et al., 2001). Embora sejam perspectivas valorativas diferentes, Tamayo (2005) pontua que ao estabelecerem o que é bom para as organizações, as pessoas estão, de certo modo, também utilizando os mesmos princípios para nortear o comportamento pessoal e, desse modo, os valores tendem a guiar as opções das pessoas em seus comportamentos.

Nesta pesquisa, será considerada a teoria funcionalista dos valores humanos (Gouveia, 1998, 2003, 2013; Gouveia et al., 2009) para averiguar a relação entre os valores pessoais e a satisfação com o trabalho. Tal teoria tem sido desenvolvida no Brasil, e replicada em estudos locais (Medeiros et al., 2012) e transculturais (Gouveia, 2013). Essa perspectiva integra modelos anteriores (Inglehart, 1990; Rokeach, 1973; Schwartz, 1994) e baseia-se na lista de necessidades básicas proposta por Maslow (1970). De modo que os valores são definidos como "conceitos ou categorias sobre estados desejáveis de existência, que transcendem situações específicas, assumem diferentes graus de importância, guiam a seleção ou avaliação de comportamentos e eventos, e representam cognitivamente as necessidades humanas" (Gouveia et al., 2009, p. 37).

Segundo Gouveia (1998, 2003, 2013) e Gouveia et al. (2009), há um consenso sobre pelo menos duas funções dos valores: eles guiam as ações (Rokeach, 1973; Schwartz, 1992, 1994) e representam cognitivamente as necessidades humanas (Inglehart, 1990; Maslow, 1970). Na teoria funcionalista, a primeira função diz respeito ao tipo de orientação, enquanto a segunda refere-se ao tipo de motivador, considerando a existência de dezoito valores básicos: sexualidade, prazer, emoção, poder, prestígio, êxito, sobrevivência, estabilidade pessoal, saúde, conhecimento, beleza, maturidade, apoio social, convivência, afetividade, tradição, religiosidade e obediência.

Os valores, tomando como referência sua primeira função, servem como princípios-guia dos comportamentos em uma orientação pessoal (individual) ou social (coletiva). Os sujeitos com orientação pessoal enfatizam o indivíduo como a unidade básica de sobrevivência, ao passo que o grupo é assim considerado pelos que adotam uma orientação social (Gouveia, 1998, 2003, 2013; Gouveia et al., 2009). Há, ainda, uma categoria de valores adjacentes aos tipos de orientação social e pessoal, que não se enquadram exclusivamente em uma dessas categorias, são os valores centrais. Assim, a função tipo de orientação compreende três categorias ou critérios: social, central e pessoal. Considera-se, ainda, que os valores centrais são a fonte dos demais (Gouveia et al., 2009; Gouveia, 2013).

A segunda função dos valores, por sua vez, os aponta como as expressões cognitivas das necessidades humanas como um motivador materialista (pragmático) ou humanitário (idealista). Valores materialistas estariam relacionados a metas concretas e ideias práticas; valores humanitários expressam ideias e princípios mais abstratos (Gouveia et al, 2009; Gouveia, 2013). As duas funções podem ainda ser integradas em uma estrutura biaxial, em que a primeira corresponde ao eixo horizontal e a segunda, ao eixo vertical. Desse cruzamento derivam-se as seis subfunções específicas dos valores: (a) Experimentação, (b) Realização, (c) Existência, (d) Suprapessoal, (e) Interativa e (f) Normativa.

Essa teoria tem sido utilizada no contexto da gestão das organizações, como demonstra três estudos empíricos, indicando que o modelo é coerente e útil na explicação de fenômenos do comportamento organizacional como o comprometimento organizacional, o bem-estar no trabalho, a fadiga e o burnout (Gouveia et al., 2009). Outro estudo (Freires, Gouveia, Bortolotti, \& Ribas, 2014) sinaliza a importância de associar a perspectiva valorativa e organizacional na compreensão de alguns fenômenos do trabalho, por exemplo, resistência à mudança organizacional. Observou-se que os funcionários de uma empresa pública que se guiam por valores 
mais idealistas resistem menos a mudanças. Desse modo, estudar a relação entre as variáveis satisfação no trabalho e valores humanos poderá ampliar a compreensão dos fenômenos organizacionais no que diz respeito aos valores da organização e aos valores humanos.

\section{MÉTODO}

Esta pesquisa de campo é de natureza transversal, expostfacto, em delineamento correlacional. Consideram-se os valores humanos como variáveis explicativas e as dimensões da satisfação no trabalho como variáveis-critério.

\section{Participantes}

Utilizando-se de uma estratégia acidental não probabilística, assumiu-se como critério de inclusão a acessibilidade e a disponibilidade dos indivíduos em participar da pesquisa. Desse modo, compôs-se uma amostra voluntária de 192 profissionais divididos em duas categorias profissionais: docentes ( $N=117)$ e técnicoadministrativos universitários $(N=75)$, todos delimitados no campus I da UEPB. Os professores da amostra são majoritariamente homens $(N=63 ; 53,8 \%)$, com idade variando entre 25 e 67 anos $(M=45,5 ; D P=9,22)$, casados ( $N=71 ; 60,7 \%)$ e católicos $(N=56 ; 47,9 \%)$, com mestrado $(N=57 ; 48,7 \%)$, renda acima de dez salários mínimos $(N=57 ; 48,7 \%)$ e tempo médio na instituição variando entre 1 ano, ou menos, até 41 anos $(M=14,2 ; D P=10,45)$. Os servidores técnico-administrativos da amostra são majoritariamente homens $(N=43 ; 57,3 \%)$, com idade variando entre 23 e 57 anos $(M=38,62 ; D P=10,84)$, casados $(N=36 ; 48 \%)$ e católicos ( $N=37 ; 49,3 \%)$, graduados $(N=45 ; 60 \%)$, com renda entre dois e quatro salários mínimos $(N=36 ; 48 \%)$ e tempo médio na instituição variando entre 1 ano, ou menos, até 36 anos $(M=12,59 ; D P=12,85)$.

\section{Instrumentos}

\section{Escala de Satisfação no Trabalho - Versão Reduzida (EST-R)}

Criada por Siqueira $(1995,2008)$, possui 15 itens, em que é solicitado ao participante que indique, em uma escala tipo likert de sete pontos $(1=$ totalmente insatisfeito; 7 = totalmente satisfeito), o quanto se sente satisfeito ou insatisfeito com cada um dos itens propostos. É composta por cinco dimensões: a primeira, denominada Satisfação com os colegas, compreende aspectos da interação entre colegas, como o espírito de colaboração, amizade e confiança entre os pares; a segunda dimensão, denominada Satisfação com o salário, diz respeito à percepção de estar recebendo remuneração justa em relação à capacidade profissional e ao esforço na execução do trabalho; a terceira dimensão, Satisfação com a chefia, diz respeito a quanto o individuo se sente contente com a capacidade do chefe em gerir o trabalho dos subordinados e interagir com eles; a quarta dimensão, Satisfação com a natureza do trabalho, diz respeito à satisfação intrínseca ao trabalho, com seu conteúdo e variedade; por fim, a quinta dimensão, Satisfação com as promoções, aborda a percepção das políticas de promoção de pessoal, o nível de contentamento com a possibilidade de ser promovido e com as promoções já adquiridas. A escala apresentou, neste estudo, coeficientes alfa de Cronbach variando de 0,82 a 0,92.

\section{Questionário de Valores Humanos Básicos (QVB)}

Criado por Gouveia, Milfont, Fischer e Santos (2008), é composto por uma lista de 18 itens (valores) que devem ser avaliados pelo respondente em uma escala tipo Likert de sete pontos $(1=$ nada importante; $7=$ totalmente importante), indicando em que grau cada valor representa um princípio-guia na vida do sujeito. É formado por seis fatores, que compõem seis subfunções dos valores: Experimentação expressa a necessidade de satisfação em sentido amplo (emoção, prazer e sexualidade), com motivador humanitário e orientação pessoal; Realização representa a necessidade de autoestima (poder, prestígio e êxito), com motivador materialista e orientação pessoal; Existência, por sua vez, representa cognitivamente as necessidades fisiológicas básicas e a necessidade de segurança (saúde, estabilidade pessoal e sobrevivência), com motivador materialista e orientação central; Suprapessoal expressa necessidades superiores de autorrealização e necessidades estéticas e de cognição (beleza, conhecimento e maturidade), sendo valores centrais de motivação humanitária; a subfunção Interacional representa as necessidades de pertença, amor e filiação (afetividade, convivência e apoio social), compreendendo um motivador humanitário e uma orientação social; por fim, a subfunção Normativa representa a necessidade de controle e manutenção da estrutura social hierárquica (obediência, religiosidade e tradição), tratando-se de uma subfunção de motivador pragmático e orientação social (Gouveia, 1998, 2003; Gouveia et al., 2009). Essa escala apresentou, neste estudo, índice de confiabilidade de 0,74. 
Por fim, foi utilizada uma ficha para caracterizar o perfil sociodemográfico (idade, sexo, escolaridade, estado civil e religião) e socio-ocupacional da amostra (categoria profissional, renda mensal e tempo de serviço).

\section{Procedimento de coleta de dados e cuidados éticos}

Os profissionais que compuseram a amostra, tanto docentes quanto técnico-administrativos universitários, foram abordados nas dependências da UEPB, em seus respectivos departamentos, onde eram, após uma breve apresentação dos objetivos da pesquisa, convidados a participar de forma anônima e voluntária. Após isso, eram solicitados a ler e assinar um Termo de Consentimento Livre e Esclarecido. O tempo de resposta não ultrapassou 10 minutos. O estudo só foi levado a cabo após a aprovação do Comitê de Ética em Pesquisa da UEPB (parecer nº. 0224.0.133.000-11), estando de acordo com as diretrizes da Resolução 466/12 do Conselho Nacional de Saúde.

\section{Procedimento de análise de dados}

Os dados foram tabulados com o auxílio do pacote Statistical Package for Social Sciences (SPSS). Os valores com os quais as dimensões da satisfação no trabalho tenham mostrado correlações parciais significantes foram introduzidos em modelos de regressão linear múltipla stepwise no intuito de averiguar a contribuição de cada valor em explicar a variância dos resultados de satisfação no trabalho. $\mathrm{O}$ uso das correlações parciais teve por objetivo evitar que as potenciais variáveis preditoras apresentassem coeficientes espúrios devido à multicolinearidade.

\section{RESULTADOS E DISCUSSÃO}

Os resultados das análises de regressão são apresentados na Tabela 1. As cinco dimensões teóricas da satisfação puderam ser preditas significativamente por um ou mais valores ou subfunções em ambas as categorias profissionais, com coeficientes estatisticamente diferentes de zero $(t>1,96)$. Considerando as diferenças nos tamanhos amostrais dos dois grupos pesquisados, principalmente o número relativamente reduzido de servidores técnico-administrativos, análises foram feitas com o intuito de estimar o poder estatístico atingido nas análises. Por meio do emprego do software $G^{*}$ Power, tendo em vista o tamanho médio do efeito encontrado em cada grupo ( $M=0,33$ para os técnicos e $M=0,23$ para os professores), foi estimado um poder equivalente a $99 \%$ para ambos os grupos.

TABELA 1. Valores preditores das dimensões ${ }^{a}$ da satisfação no trabalho

\begin{tabular}{|c|c|c|c|c|c|c|}
\hline $\begin{array}{c}\text { Dimensões da satisfação no } \\
\text { trabalho }\end{array}$ & $\begin{array}{l}\text { Categoria } \\
\text { profissional }\end{array}$ & Preditor & $\boldsymbol{R}$ & $R^{2}$ & $\beta$ & $t$ \\
\hline \multirow[b]{2}{*}{ Satisfação com os colegas } & Professores & Prazer & 0,307 & 0,09 & $-0,307$ & $-3,404^{* *}$ \\
\hline & Técnicos & $\begin{array}{l}\text { Estabilidade } \\
\text { pessoal }\end{array}$ & 0,422 & 0,17 & 0,422 & $3,870^{\star *}$ \\
\hline \multirow[b]{2}{*}{ Satisfação com a chefia } & Professores & Interacional & 0,235 & 0,05 & 0,235 & $2,536^{\star}$ \\
\hline & Técnicos & $\begin{array}{l}\text { Estabilidade } \\
\text { pessoal }\end{array}$ & 0,322 & 0,10 & 0,322 & $2,963^{\star *}$ \\
\hline \multirow{2}{*}{ Satisfação com o salário } & Professores & Maturidade & 0,19 & 0,03 & $-0,19$ & $-2,037^{\star}$ \\
\hline & Técnicos & Emoção & 0,256 & 0,05 & 0,256 & $2,232^{*}$ \\
\hline Satisfação com as promoções & Professores & Convivência & 0,221 & 0,05 & 0,221 & $2,393^{*}$ \\
\hline \multirow{2}{*}{$\begin{array}{l}\text { Satisfação com a natureza do tra- } \\
\text { balho }\end{array}$} & \multirow{2}{*}{ Técnicos } & $\begin{array}{l}\text { Estabilidade } \\
\text { pessoal }\end{array}$ & 0,454 & 0,18 & 0,365 & $3,427^{\star *}$ \\
\hline & & Emoção & - & - & 0,287 & $2,695^{\star *}$ \\
\hline
\end{tabular}

Nota. ${ }^{a}$ As dimensões Satisfação com as promoções e Satisfação com a natureza do trabalho não foram preditas significantemente por nenhum dos valores entre os técnicos e professores, respectivamente. ${ }^{* \star} p<0,01 ;{ }^{*} p<0,05$.

\section{Preditores da Satisfação com os colegas}

Conforme pode ser visualizado na Tabela 1 , na amostra de professores o valor Prazer $(\beta=-0,31)$ foi capaz de explicar quase $10 \%$ da variância na dimensão Satisfação com os colegas. Esse resultado sugere que o fato 
de o professor valorizar a satisfação dos próprios desejos (note-se que o valor Prazer situa-se na subfunção Experimentação, de orientação pessoal e motivador idealista) parece ter o poder de influenciar negativamente a satisfação com o relacionamento estabelecido com os pares, que demanda muitas vezes a abdicação da satisfação de necessidades individuais em prol da coletividade. A percepção da impossibilidade imediata de realização de uma meta valorizada - neste caso a satisfação dos desejos individuais - através do trabalho oferece sua parcela de contribuição para a instalação da insatisfação com essa dimensão (Locke, 1969, 1976, 1984).

Por outro lado, na amostra de servidores técnico-administrativos, apenas Estabilidade pessoal $(\beta=0,42)$ foi considerado preditor significativo, com coeficiente padronizado de regressão da ordem de 0,42 , explicando $17 \%$ da variância total da Satisfação com os colegas.

\section{Preditores da Satisfação com a chefia}

$\mathrm{Na}$ amostra de professores, somente a subfunção Interativa obteve índices satisfatórios de predição da Satisfação com a chefia. Esse resultado aponta a valorização das relações de grupo como responsável pelo incremento da satisfação com os chefes que, nesse caso, são também colegas diretos (professores). Resultados similares foram encontrados por Noordin e Jusoff (2010), os quais identificaram que profissionais que endossaram valores coletivistas tenderam a apresentar maiores índices de satisfação no trabalho (ver também Calvosa et al., 2011; Calvosa et al., 2011). O valor Estabilidade pessoal, na amostra de técnico-administrativos, foi capaz de predizer significativamente a satisfação com a dimensão chefia, explicando $10 \%$ da variância. A importância atribuída a esse valor, que representa a necessidade de segurança e estabilidade, entre esses profissionais, tem poder de influenciar a satisfação com as relações estabelecidas com os colegas e com os chefes. Esse resultado pode ser atribuído, entre outros fatores, à natureza do emprego público, em que a competitividade no ambiente de trabalho parece ser uma realidade menos acentuada quando comparada às instituições privadas. Embora haja evidências de que profissionais do setor privado apresentam maiores índices de satisfação quando comparados aos do setor público (Pillay, 2009), o fato de não perceber o colega como um rival ou concorrente direto, bem como o estilo menos autoritário das chefias torna o profissional menos inseguro em relação à sua condição atual e futura, favorecendo a satisfação com os seus pares e superiores. Assim, consonante com Locke (1969, 1976, 1984), a percepção de que os colegas de trabalho e chefes podem auxiliar na manutenção da segurança e estabilidade valorizadas pelo trabalhador pode ser um elemento responsável pelo incremento de sua satisfação com esses atores organizacionais.

\section{Preditores da Satisfação com o salário}

A satisfação dos professores com o seu salário foi predita pelo valor Maturidade. O dado relevante deste resultado é a direção negativa da predição, em que o aumento de uma unidade padronizada nas pontuações do valor Maturidade reflete-se no decréscimo de 0,19 unidades padronizadas da Satisfação com o salário. Embora a magnitude dos resultados seja discreta, ela sugere que quanto maior a valorização do desenvolvimento das capacidades individuais e a realização de metas de médio e/ou longo prazo, menor é a Satisfação com o salário.

De maneira diversa, a satisfação dos técnico-administrativos com os seus provimentos foi predita de maneira positiva pelo valor Emoção. Embora a proporção de variância explicada seja relativamente pequena, o resultado sugere que aqueles profissionais que valorizam a fruição da vida e a busca de aventuras tendem a sentir-se mais satisfeitos com o seu salário, na proporção de aumento da ordem de 0,25 nas pontuações de Satisfação com o salário associadas ao aumento de uma unidade padronizada nas pontuações do valor Emoção. Este resultado carece de suporte teórico, uma vez que o valor Emoção atende teoricamente a necessidades pessoais idealistas, quando se esperaria que a Satisfação com o salário pudesse ser predita por um valor pessoal materialista (Gouveia et al., 2009).

\section{Preditores da Satisfação com as promoções}

Esta dimensão pôde ser predita pelo valor Convivência somente na amostra de professores. Embora a explicação seja de apenas 5\% da variância, o resultado sugere que o sentimento de pertença e comunidade valorizado pelos professores tende a associar-se a uma maior satisfação com a política de promoções da universidade (para resultados similares, ver Noordin \&Jusoff, 2010). Vale salientar que os professores da amostra são beneficiados pelo Plano de Cargos, Carreira e Remuneração da universidade que compõe o lócus de pesquisa, gozando do benefício da ascensão por tempo de serviço (horizontal) e por titulação obtida (vertical). Os servidores 
técnico-administrativos, por sua vez, somente gozam do benefício da ascensão horizontal, embora não haja evidências de que seja este o motivo para a não identificação de valores preditores desta dimensão.

\section{Preditores da Satisfação com a natureza do trabalho}

$\mathrm{Na}$ amostra de servidores técnico-administrativos, a dimensão Satisfação com a natureza do trabalho pôde ser predita pelos valores Estabilidade pessoal e Emoção. Esse resultado é dissonante com a proposta teórica do modelo adotado, segundo a qual os valores Estabilidade pessoal e Emoção atendem a necessidades que são conflitantes ou independentes (Gouveia et al., 2009). O respectivo dado ainda pode ser tomado como uma particularidade da amostra, admitindo a necessidade de estudos mais concludentes com fins de justificativa teórica.

Considera-se que o objetivo proposto foi cumprido, e os resultados confirmam a hipótese subjacente ao estudo: a da existência de antecedentes axiológicos para as dimensões da satisfação. Este achado ganha suporte por tratar-se de duas variáveis cujo lastro é comum - a natureza motivacional tanto dos valores (Gouveia, 2003) quanto da satisfação no trabalho (Maslow, 1970).

Digno de nota é o fato de que, apesar de identificados antecedentes valorativos da satisfação, valores diferentes predisseram de maneira também diferente as dimensões da satisfação em cada categoria profissional. Em outras palavras, parece haver um efeito de interação entre as variáveis satisfação no trabalho, valores humanos e categoria profissional. A título de exemplo, entre os professores, nenhum valor mostrou-se antecedente à Satisfação com o conteúdo do trabalho, ao passo que, na amostra de servidores técnico-administrativos, a Satisfação com as promoções não pôde ser predita por nenhum dos valores considerados.

Ainda assim, foi possível identificar os valores com maior poder explicativo sobre algumas dimensões da satisfação em cada categoria profissional, sobretudo a dimensão Colegas, que obteve os mais elevados coeficientes de regressão neste estudo. Como visto, a satisfação dos professores com seus colegas foi predita negativamente e com maior poder explicativo pelo valor Emoção, sendo este o seu antecedente mais forte. Por outro lado, entre os servidores técnico-administrativos, foi identificado enquanto antecedente axiológico mais poderoso da dimensão Colegas o valor Estabilidade pessoal. Esses resultados vêm contribuir para o maior entendimento acerca das relações estabelecidas entre os valores e as variáveis relacionadas ao trabalho, campo que ainda carece de produção científica massiva (Tamayo et al., 2001; Gouveia et al., 2009).

Por fim, considera-se que os resultados obtidos nesta pesquisa poderão servir de subsídio para a implementação de políticas que favoreçam ou que fortaleçam as características identificadas como antecedentes das dimensões da satisfação no trabalho.

\section{REFERÊNCIAS}

Calvosa, M. V. D., Serra, F. A. R., \& Almeida, M. I. R (2011). Quais são as prioridades axiológicas dos líderes empresariais? Análises dos seus valores pessoais a partir do Inventário de Valores de Schwartz. Anais eletrônicos do III Encontro de Gestão de Pessoas e Relações de Trabalho. João Pessoa: Universidade Federal da Paraíba Recuperado de http://www. anpad.org.br/diversos/trabalhos/EnGPR/engpr_2011/2011_ENGPR75.pdf

Calvosa, M. V. D., Silva, P. L. C., Serra, F. A. R., \& Almeida, M. I. R. (2011). Quais são as prioridades axiológicas dos docentes de IES? Uma survey sobre a hierarquização de seus valores pessoais. Anais do XXXV Encontro da ANPAD. Rio de Janeiro: ANPAD. Recuperado de http://www.ead.fea.usp.br/eadonline/grupodepesquisa/publica\%C3\%A7\%C3\%B5es/marcello/17.pdf

Carlotto, M. S. (2004). Síndrome de burnout e características de cargo em professores universitários. Revista Psicologia: Organizações e Trabalho, 4(2), 145-162.

Carlotto, M. S. (2010). Síndrome de burnout: Diferenças segundo níveis de ensino. Revista PsicoPUCRS, 41(4), 495-502.

Carlotto, M. S., \& Câmara, S. G. (2007). Preditores da síndrome de burnout em professores. Revista Semestral da Associação Brasileira de Psicologia Escolar e Educacional, 11(1), 101-110.

Cavadas, F. S. (2014). Valores e satisfação no trabalho: Que relação? (Dissertação de mestrado). Recuperado de http:// repositorio-aberto.up.pt/bitstream/10216/77243/2/104888.pdf

Lei 13.696, de 29 de dezembro de 2007 (2007, 29 de dezembro). Institui o Plano de Cargos, Carreira e Remuneração do pessoal técnico administrativo da Universidade Estadual da Paraíba e dá outras providências. Diário Oficial da União. Recuperado de http://static.paraiba.pb.gov.br/diariooficial_old/diariooficial29122007.pdf 
Ferreira, M. C., \& Assmar, E. M. L. (2004). Cultura, satisfação e saúde nas organizações. In A. Tamayo (Org.), Cultura e saúde nas organizações (pp. 102-126). Porto Alegre: Artmed.

Freires, D. A. N., Gouveia, V. V., Bortolotti, S. L. V., \& Ribas, F. T. T. (2014). Resistência à mudança organizacional: Perspectiva valorativa e organizacional. PsicoPUCRS, 45(4), 513-523. doi: http://dx.doi.org/10.15448/1980-8623.2014.4.16220

Garcia, L. P., \& Benevides-Pereira, A. M. T. (2003). Investigando o burnout em professores universitários. Revista Eletrônica Interação Psy, 1(1), 76-89.

Gouveia, V. V. (1998). La naturaleza de los valores descriptores del individualismo y del colectivismo: Una comparación intra e intercultural (Tese de doutorado não publicada). Universidad Complutense de Madrid, Madri.

Gouveia, V. V. (2003). A natureza motivacional dos valores humanos: Evidências acerca de uma nova tipologia. Estudos de Psicologia, 8(3), 431-443.

Gouveia, V. V. (2013). Teoria funcionalista dos valores humanos. São Paulo: Casa do Psicólogo.

Gouveia, V. V., Milfont, T. L., Fischer R., \& Coelho, J. A. P. M. (2009). Teoria funcionalista dos valores humanos: Aplicações para organizações. Revista de Administração Mackenzie, 10(3), 34-59.

Gouveia, V. V., Milfont, T. L., Fischer, R. \& Santos, W. S. (2008). Teoria funcionalista dos valores humanos. In M. L. M. Teixeira (Org.), Valores humanos e gestão: Novas perspectivas (pp. 47-80). São Paulo: Editora Senac.

Herzberg, F. (1971). The motivation-hygiene theory. In F. Herzberg, Work and the nature of man (2 ed., pp. 71-91). Cleveland: World Publishing.

Inglehart, R. (1990). Culture shift in advanced industrial society. Princeton: Princeton University Press.

Locke, E. A. (1969). What is job satisfaction. Organizational Behavior and Human Performance, 4(4), 309-336.

Locke, E. A. (1976). The nature and causes of job satisfaction. In M. D. Dunnette (Org.), Handbook of industrial and organizational psychology (pp. 1297-1349). Chicago: Rand McNally.

Locke, E. A. (1984). Job satisfaction. In M. Gruneberg \& T. Wall (Orgs.), Social psychology and organizational behavior (pp. $93-$ 117). New York: John Wiley \& Sons.

Martinez, M. C., \& Paraguay, A. I. B. B. (2003). Satisfação e saúde no trabalho: Aspectos conceituais e metodológicos. Cadernos de Psicologia Social do Trabalho, 6(1), p. 59-78.

Maslach, C. (2009). Comprendiendo el burnout. Revista Ciência \& Trabajo, 11(32), 37-43.

Maslow, A. H. (1970). A theory of human motivation. In A. H. Maslow, Motivation and personality (2 ed., pp. 35-58). New York: Harper \& Row.

Medeiros, E. D., Gouveia, V. V., Gusmão, E. E. S., Milfont, T. L., Fonseca, P. N., \& Aquino, T. A. A. (2012). Teoria funcionalista dos valores humanos: Evidências de sua adequação no contexto paraibano. Revista de Administração Mackenzie, 13(3), 18-44. doi: http://dx.doi.org/10.1590/\$1678-69712012000300003

Noordin, F., \& Jusoff, K. (2010). Individualism-collectivism and job satisfaction between Malaysia and Australia. International Journal of Education Management, 24(2), 159-174. doi: http://dx.doi.org/10.1108/09513541011020963

Paris, L., \& Omar, A. (2008). Predictores de satisfacción laboral en medicos y enfermeros. Estudos de Psicologia, 13(3), 233-244. doi: http://dx.doi.org/10.1590/S1413-294X2008000300006

Pillay, R. (2009). Work satisfaction of professional nurses in South Africa: A comparative analysis of the public and private sectors. Human Resources for Health, 7(15), 1-10. doi: 10.1186/1478-4491-7-15

Rokeach, M. (1973). The nature of human values. New York: Free Press.

Schwartz, S. H. (1992). Universals in the context and structure of values: Theoretical advances and empirical tests in 20 countries. In M. Zanna (Org.), Advances in experimental social psychology (pp. 1-65). Orlando: Academic Press.

Schwartz, S. H. (1994). Are there universal aspects in the structure and contents of human values? Journal of Social Issues, 5O(1), 19-45. doi: 10.1111/j.1540-4560.1994.tb01196.x

Silva, N. (2015). Motivação e satisfação no trabalho. In P. F. Bendassolli \& J. E. Borges-Andrade (Orgs.), Dicionário de psicologia do trabalho e das organizações (pp. 453-461). São Paulo: Casa do Psicólogo.

Siqueira, M. M. M. (1995). Antecedentes de comportamentos de cidadania organizacional: Análise de um modelo pós-cognitivo (Tese de doutorado não publicada). Universidade de Brasília, Brasília.

Siqueira, M. M. M. (2008). Satisfação no trabalho. In M. M. M. Siqueira (Org.), Medidas do comportamento organizacional: Ferramentas de diagnóstico e de gestão (pp. 265-274). Porto Alegre: Artmed. 
Siqueira, M. M. M., \& Gomide-Júnior, S. (2004). Vínculos do indivíduo com o trabalho e com a organização. In J. C. Zanelli, J. E. Borges-Andrade \& A. V. B. Bastos (Orgs.), Psicologia, organizações e trabalho no Brasil (pp. 300-328). Porto Alegre: Artmed.

Siqueira, M. M. M., \& Martins, M. C. F (2013). Promoção de saúde e bem-estar em organizações. In L. O. Borges \& L. Mourão (Orgs.), O trabalho e a organização: Atuações a partir da psicologia (pp. 619-643). Porto Alegre: Artmed.

Siqueira, M. M. M., \& Padovam, V. A. R. (2008). Bases teóricas de bem-estar subjetivo, bem-estar psicológico e bem-estar no trabalho. Psicologia: Teoria e Pesquisa, 24(2), 201-209.

Siqueira, M. M. M., Orengo, V., \& Peiró, J. M. (2014). Bem-estar no trabalho. In M. M. M. Siqueira (Org.), Novas medidas do comportamento organizacional: Ferramentas de diagnóstico e de gestão (pp. 39-51). Porto Alegre: Artmed.

Tamayo, A. (1998). Valores organizacionais: Sua relação com satisfação no trabalho, cidadania organizacional e comprometimento afetivo. Revista de Administração, 33, 56-63.

Tamayo, A. (2001). Prioridades axiológicas, atividade física e estresse ocupacional. Revista de Administração Contemporânea, 5(3), 127-147.

Tamayo, A. (2005). Impacto dos valores pessoais e organizacionais sobre o comprometimento organizacional. In A. Tamayo \& J. B. Porto (Orgs.), Valores e comportamento nas organizações (pp. 160-186). Petrópolis: Editora Vozes.

Tamayo, A., \& Paschoal, T. (2003). A relação da motivação para o trabalho com as metas do trabalhador. Revista de Administração Contemporânea, 7(4), 33-54.

Tamayo, A., Souza, M. G. S., Vilar, L. S., Ramos J. L., Albernaz, J. V., \& Ferreira, N. P. (2001). Prioridades axiológicas e comprometimento organizacional. Psicologia Teoria e Pesquisa, 17(1), 27-35.

Universidade Estadual da Paraíba (2008). Manual de cargos, funções e competências dos servidores técnicos administrativos da Universidade Estadual da Paraíba. Campina Grande: Eduepb. 